\title{
The Relation between Entecavir Dose and Therapeutic Effect in the Treatment of Hepatitis B Virus
}

\author{
FANG LU, HUI WANG AND QINGLING YU* \\ Tenth Hepatology Department, Qingdao No. 6 People's Hospital, Qingdao, 266033, China
}

Lu et al.: Entecavir Dose and Therapeutic Effect in the Treatment of HBV

This study investigated the relation between entecavir dose and therapeutic effect in the treatment of chronic hepatitis B. About 180 chronic hepatitis B patients were enrolled as research subjects. They were randomly divided into the control group accepting $0.5 \mathrm{mg}$ of entecavir and the research group accepting $1.0 \mathrm{mg}$ of entecavir, each containing 90 patients. Indices monitored included hepatitis B virus-DNA, liver function (alanine aminotransferase, total bilirubin), alanine aminotransferase recurrence, hepatitis $B$ virus-DNA negative conversion, $\mathrm{HBeAg} / \mathrm{HBeAb}$ negative conversion were analyzed comparatively. After accepting different treatments, the hepatitis $B$ virus-DNA level was lower significantly in the research group than that in the control group, $p<0.05$. The research group gained more significant improvement of liver function, alanine aminotransferase recurrence, hepatitis B virus-DNA negative conversion rate and $\mathrm{HBeAg} / \mathrm{HBeAb}$ negative conversion rate, $\mathbf{p}<\mathbf{0 . 0 5}$. It can be concluded that entecavir is an ideal antihepatitis $B$ viral drug, which can help patients improve their treatment efficiency and has high reliability.

Key words: Entecavir, hepatitis B virus, applied dose, therapeutic effect, comparative observation 
Currently, the number of hepatitis B virus (HBV) patients has reached about 300 million worldwide and nearly one million die from diseases related to $\mathrm{HBV}$ each year ${ }^{[1,2]}$. In China, the number of people infected with chronic hepatitis $\mathrm{B}$ (CHB) has reached 93 million at present, and nearly 300000 deaths per year result from hepatitis B related diseases ${ }^{[3-5]}$.

HBV (fig. 1) is a DNA virus replicating through reverse transcription. The HBV can be transformed into covalently closed circular DNA (cccDNA) after entering hepatocytes and then remains hidden in the nucleus. So it can hardly be completely removed even with antiviral therapy. If patients are immunodeficient due to long-term use of immunosuppressive agents or chemotherapy or radiotherapy, cccDNA can be transferred into an active replication state, leading to long-term HBV infection ${ }^{[6]}$. Entecavir (ETV) is a guanine nucleotide analogue. In this study, the relation between entecavir dose and therapeutic effect in treatment of $\mathrm{CHB}$ was investigated.

About $180 \mathrm{CHB}$ patients were enrolled as research subjects. Fig 2 shows the imaging examination of a CHB patient. The patients meeting inclusion criteria included those with chronic HBV infection history, those with positive HBsAg for more than half a year, those with the DNA level of HBV being equal to or larger than $20 \mathrm{mEq} / \mathrm{ml}$; those with alanine aminotransferase (ALT) ranging between normal value and 10 times of normal value (upper limit), with serum total bilirubin (TBIL) of $42.75 \mathrm{~mol} / 1$ or below, with the upper limit of serum creatinine level being 1.5 times of normal value, with serum albumin of $30 \mathrm{~g} / \mathrm{l}$ or above ${ }^{[7]}$. However, patients with human immunodeficiency virus, those accepting recent administration of antivirals, interferon alpha or other antiHBV drugs in recent $24 \mathrm{w}$, those with history of pancreatitis, pregnant or lactating women were

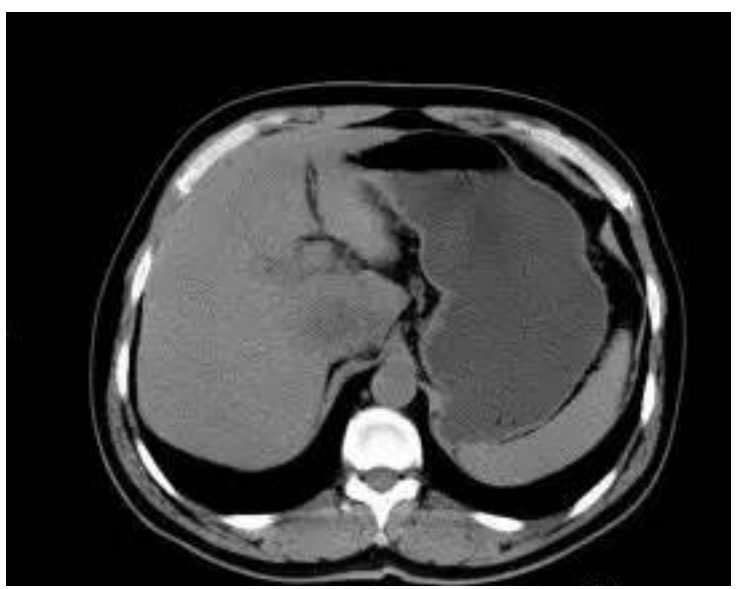

Fig. 1: Chronic hepatitis B (CHB)

Special Issue 2, 2020

Indian Journal of Pharmaceutical Sciences

79 
Although common interferon, pegylated interferon and several antihepatitis B virus nucleoside drugs have been developed in recent decades, the efficacy of interferon is limited, and nucleoside drugs need long-term application (fig. 3). Since nucleoside drugs have been on the market for a short time, the long-term treatment efficacy of these drugs is still to be discovered ${ }^{[8]}$.

Entecavir is a new generation of nucleoside antiHBV drug. In vitro experiments showed that low concentration of entecavir could inhibit HBV replication but its cytotoxicity was low, so the advantage of selective therapeutic index was higher. In the experiment based on animal model of marmots with HBV, 0.1 or $1.0 \mathrm{mg} / \mathrm{kg}$ of this drug could significantly inhibit virus replication and the reduction of viremia to $7 \log _{10}$ could be achieved ${ }^{[9]}$. Moreover, after stopping the drug, the virus rebound was relatively slow. According to the study on cell and animal models, entecavir has been demonstrated to be effective in treatment of CHB.

The research group patients treated with entecavir at a dosage of $1.0 \mathrm{mg}$ had a more significant reduction of HBV-DNA level, a more significant improvement of liver function, as well as higher ALT recurrence rate, $\mathrm{HBV}-\mathrm{DNA}$ negative conversion rate and $\mathrm{HBeAg} /$ $\mathrm{HBe} \mathrm{Ab}$ negative conversion rate. Moreover, no serious clinical adverse reactions were observed during the treatment, so this drug has higher safety and reliability. The results of this study are consistent with a reported study ${ }^{[10]}$, as shown in fig. 4.

In conclusion, entecavir is a typical guanine nucleoside analogue against HBV. Entecavir was administered orally, it is taken up into the liver and phosphorylated to become the active triphosphate. Then, it competes with guanosine triphosphate, the substrate of HBV-DNA polymerase, inhibits the activity of HBV polymerase and blocks HBV replication, so as to prevent the

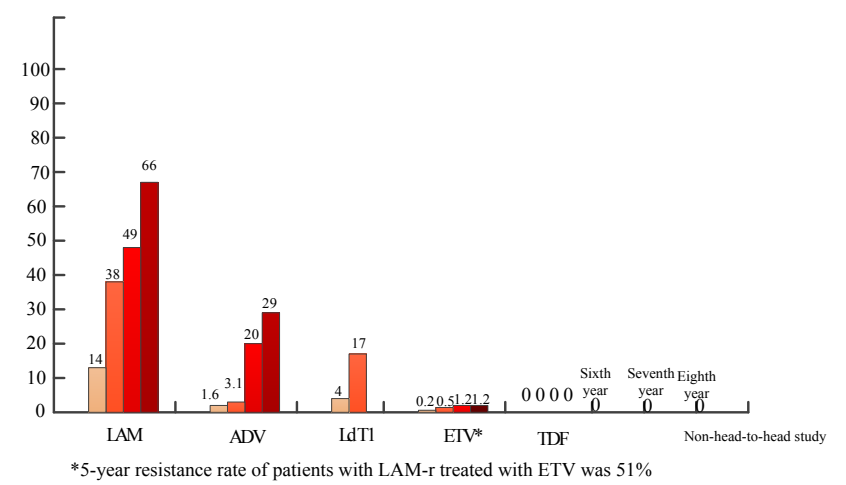

Fig. 3: The resistance rate of nucleoside drugs

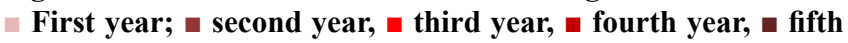
year

80

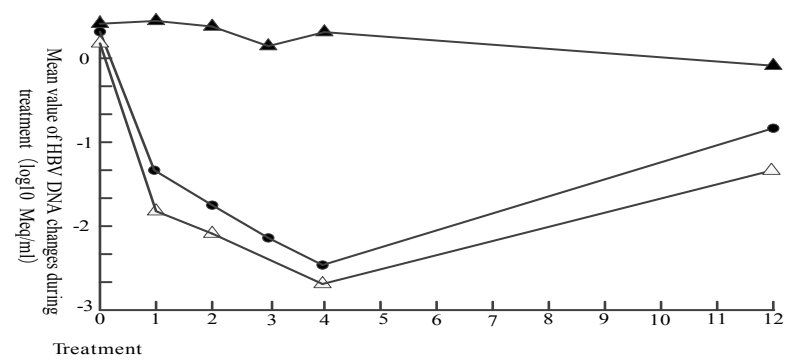

Fig. 4: Comparison of study results

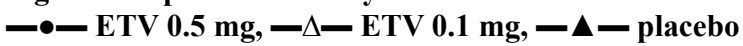

hepatocytes infected with HBV from developing immune injury. In addition, entecavir has extremely high antiHBV activity and is a highly selective HBV polymerase inhibitor, which could inhibit viral replication rapidly and effectively. The drug is safe to treat hepatitis B and the virus resistance to this drug is extremely low. Entecavir is of great clinical value in treating CHB.

\section{REFERENCES}

1. Chen Y, Qian S, Xie Y, Yang F. Comparison of the efficacy of lamivudine and entecavir in the prevention of reactivation of hepatitis B virus after chemotherapy for non-Hodgkin's lymphoma and analysis of the risk factors for recurrence of hepatitis B. Zhejiang Med J 2016;36(11):941-4.

2. Jiang Z, Zhang J, Yu Y, Gu S, Liu H. Observation of therapeutic effect of entecavir combined with peg-interferon $\alpha-2 a$ in the treatment of refractory chronic hepatitis B HBeAg serologic conversion. Liver 2016;21(08):644-7.

3. Fan L, Shen Q, Li H, Zheng N, Gao G, Hu Y. Evaluation of the therapeutic effect of entecavir combined with compound soft-liver tablets on hepatic fibrosis based on acoustic pulse radiative force imaging. Chin Arch Tradit Chin Med 2015;33(04):853-85.

4. Muheremu A, Sun Y, Yan K, Yu J, Zheng S, Tian W. Effect of Anterior Cervical Discectomy and Fusion on Patients with Atypical Symptoms Related to Cervical Spondylosis. J Neurol Surg A Cent Eur Neurosurg 2016;12(08):1110-4.

5. Shi S, Zheng S, Li XF, Yang LL, Liu ZD, Yuan W. Comparison of a Stand-Alone Anchored Spacer Versus Plate-Cage Construct in the Treatment of Two Noncontiguous Levels of Cervical Spondylosis: A Preliminary Investigation. World Neurosurg 2016;10(89):232-6.

6. Zhao Y, Zhu P. Observation of therapeutic effect of reimplementation of entecavir antiviral therapy on recurrent hepatitis b after irregular stopping of entecavir. Hebei Med J 2018;40(09):1399-401.

7. Zhang X. Analysis of the relationship between dose and efficacy of entecavir against hepatitis b virus. Jilin Med J 2017;38(05):931-2.

8. Bai J, Yu K, Sun Y, Kong L, Shen Y. Prevalence of and risk factors for Modic change in patients with symptomatic cervical spondylosis: an observational study. J Pain Res 2018;12(11):780-6. 
9. Bhagavathula VSS, Arimappamagan A, Lafazanos S, Pruthi N. Syringomyelia secondary to cervical spondylosis: Case report and review of literature. J Neurosci Rural Pract 2017;5(5):1246-53.

10. Moustafa IM, Diab AAM, Hegazy FA, Harrison DE. Does rehabilitation of cervical lordosis influence sagittal cervical spine flexion extension kinematics in cervical spondylotic radiculopathy subjects? J Back Musculoskelet Rehabil 2016;30(4):650-60
This is an open access article distributed under the terms of the Creative Commons Attribution-NonCommercial-ShareAlike 3.0 License, which allows others to remix, tweak, and build upon the work non-commercially, as long as the author is credited and the new creations are licensed under the identical terms

This article was originally published in a special issue: Special issue on "Drug Development and Human Health in China"

Indian J Pharm Sci 2020:82(1)spl issue2;78-81 